\title{
Racionalidade da Eficácia em Parceria em um Almoxarifado Central de um Hospital Público: uma reflexão teórica a partir da Abordagem de Guerreiro Ramos
}

\author{
Adriano Izhar Cansanção - adrianoizhar@hotmail.com ${ }^{1}$ \\ Denilson Bezerra Marques - marquesdb@gmailcom²
}

Resumo - O objetivo deste trabalho é refletir sobre a racionalidade em parceria que orienta o processo de estruturação de um sistema eficaz para o abastecimento de um almoxarifado de um hospital público. O objetivo é alcançado através de análise de conteúdo, elaborada de acordo com o método de Bardin (2010) e vinculou as categorias teóricas desenvolvidas por Ramos (1983). Os resultados apresentaram a necessidade de estruturar a comunicação do almoxarifado central em tempo hábil para possibilitar os atendimentos clínicos, cirúrgicos, ambulatoriais, dentre outros em um Hospital Público.

Palavras-chave: Eficácia em Parceria. Almoxarifado. Hospital Público. Ação Administrativa. Fato Administrativo.

\section{Rationality of Partnership Effectiveness in a Warehouse Center of a Public Hospital: a theoretical reflection from the Guerreiro Ramos Approach}

\begin{abstract}
The aim of this paper is to reflect on the rationality in partnership that guides the process of structuring an effective system to supply a warehouse in a public hospital. The objective is achieved through content analysis, elaborated according to the method of Bardin (2010) and linked the theoretical categories developed by Ramos (1983). The results showed the need to structure the communication of the central warehouse in a timely manner to enable clinical, surgical, outpatient care, among others in a public hospital.
\end{abstract}

Keywords: Partnership Effectiveness. Warehouse. Public hospital. Administrative action. Administrative Fact. 


\section{INTRODUÇÃO}

O objetivo geral deste trabalho é refletir sobre a racionalidade da ação gerencial que orienta o processo de estruturação de um sistema administrativo em um almoxarifado de um hospital público, doravante designado por Hospital @. Para Ramos (I983), o tipo ideal de ação é substantiva e equilibra fins e meios organizacionais e o tipo ideal de fato administrativo ocorre quando as pessoas se comunicam em tempo eficaz. Os objetivos específicos deste trabalho são analisar os elementos que distanciam a gestão dos pontos ideais dos fatos e ações administrativas e uma forma de alcançá-los.

O Hospital@ realiza mensalmente mais de I4.00o consultas, 36.000 exames laboratoriais, 4.500 exames por imagem, I.I00 internações e 720 cirurgias, de acordo com levantamento divulgado no site oficial do hospital em 2I de setembro de 20I8. Mas, de acordo com evidências documentais, há desabastecimentos, escassez de recursos financeiros, atrasos nas entregas e urgências.

O Hospital @ utiliza-se de memorandos para oficializar seu processo comunicacional e informar demandas. No memorando 302/2015, por exemplo, o chefe da unidade de nefrologia revela uma relação insumo/atendimento: "caso as soluções não cheguem, os atendimentos vão paralisar". Os atendimentos não ocorrem sem insumos e este registro documental revela a importância do almoxarifado, setor que armazena reagentes químicos, laboratoriais, água mineral, etiquetas identificadoras de tipo sanguíneo, dentre outros materiais que, se faltarem, paralisam os atendimentos.

De forma semelhante a Weber (2004), que partiu de registros documentais para detectar a ética do sistema capitalista, este trabalho também parte de documentos e percebe um vínculo entre práxis e racionalidade gerenciais, avançando em uma perspectiva além da weberiana, que focaliza a racionalidade de forma principal aos ditames da instrumentalidade. Neste trabalho, em função da racionalidade estar principalmente ancorada na substancialidade, o vínculo percebido pressupõe haver uma ligação entre eficácia, comunicação e tempo de forma idêntica à formulada por Ramos (I983).

Os dados coletados subordinam-se ao preconizado pela Análise de Conteúdo proposta por Bardin (20I0), cujas categorias extraídas a partir de Ramos (1983) permitem desenvolver uma interpretação focada em ações administrativas e fatos administrativos.

As ações administrativas divulgam racionalidades coletivas e individuais. A modalidade de ação social é dotada de racionalidade funcional em que seus agentes a exercem sob a validade de uma ética da responsabilidade à organização. A razão da ação administrativa pode ser entendida como eficácia, a operação produtiva de uma combinação de recursos e meios, tendo em vista alcançar objetivos.

Já os fatos administrativos revelam um complexo de elementos, resultantes da ação de diferentes pessoas em níveis de decisão, no desempenho de funções que limitam e/ou orientam as atividades humanas associadas. Os fatos administrativos são exteriores em relação à consciência dos indivíduos, podem ser coercitivos ou passíveis de coerção sobre as consciências deles. 
Ações e fatos administrativos decorrentes da prática de agentes de um almoxarifado em um hospital público são o objeto deste trabalho, que levanta problemas que permeiam a estrutura (atitudes, estrutura ou pessoas) gerencial do setor, particularmente aquela que se expressa através do sistema da gestão informatizada. Com a adaptação das categorias retiradas do trabalho de Ramos (1983), percebem-se problemas que vão desde a dimensão morfológica do fato (elemento aestrutural) à dimensão que encontra a racionalidade gerencial ou administrativa (elemento estruturante).

O sistema de gestão informatizado do Hospital @ produz uma informação de consumo que é mal interpretada, um problema aestrutural (sistema de gestão informatizado), mas que se torna basilar aos indivíduos, que a partir da geração de sua informação, elaboram suas decisões e tornam os departamentos "alheios" à própria configuração gerencial. Isso torna a lógica do abastecimento, a partir do almoxarifado, desfigurada, e entra em descompasso com os demais departamentos que mantém relação institucional com este.

A incompreensão dos dados é propagada por um ambiente calcado em uma estrutura hierárquica que tende a bloquear questionamentos e interpretações por parte dos agentes envolvidos dos distintos departamentos do hospital. Esta incompreensão, decorrente da comunicação documental, ajuda a instalar um clima organizacional que promove nos gestores um tipo de isolamento gerencial. Isso os leva a comunicar a falta do material quando o insumo já está para acabar. Como consequência, este tipo de situação implica um ambiente sem a comunicação face-a-face, se torna um problema estruturante para a racionalidade gerencial verificada no setor de almoxarifado por definir a comunicação do ambiente.

Entretanto, percebe-se haver uma relação pontual entre dois gestores que convocam suas racionalidades para atenderem às demandas. Os gestores desenvolvem uma racionalidade em parceria que evidencia eficácia e este artigo descreve as bases racionais da ação e o impacto nos níveis do fato administrativo.

\section{REFERENCIAL TEÓRICO}

A base deste artigo é à ciência administrativa, já que, por vezes, a Administração assume caráter técnico. Um exemplo é o termo just-in-time. Manuais constroem uma reputação científica para o termo que significa realizar uma ação no momento apropriado (MOTTA, 1996).

Motta revisa a literatura e conclui que just-in-time é "única e exclusivamente, uma técnica que utiliza várias normas e regras para modificar o ambiente produtivo" (MOTTA, I996, p. I29). O exame semântico e epistemológico de termos como o just-in-time evidencia a redução a ambientes produtivos na Ciência da Administração.

Ramos (I983) considera a Administração como ciência e delimita os ambientes produtivos. A tábua das categorias é a Sociologia das Organizações, campo epistemológico que analisa a produção, o ambiente, as particularidades, uma maior gama de elementos, com as duas macro categorias ação administrativa e fato administrativo.

Para a ação administrativa, Ramos (1983) se inspira em Max Weber (I999), autor que considera racionalidades sistemáticas como de fins e valores, particulariza que uma pessoa regida por uma racionalidade de fins pode se conectar aos objetivos, já o indivíduo que decide por 
conta da racionalidade de valores pode ser direcionado pela noção de dever, dignidade, beleza, religião (WEBER, I999, p. I5).

Ramos (1983) desenvolve as categorias da racionalidade instrumental e substantiva inspirado nestes conceitos weberianos. Uma organização é instrumental quando se foca nos fins e substantiva quando alcança objetivos e realça valores individuais.

Com relação ao fato administrativo, as bases científicas são fornecidas pelo sociólogo Émile Durkheim e as categorias possuem níveis e objetivam a eficácia organizacional. Para o autor, "a eficácia é mensurada por tempo e comunicação" (RAMOS, I983, p. I2), que são elementos estruturantes.

A comunicação pode ser: (i) vertical - quando hierárquica, e (ii) horizontal - quando os atores sociais chegam a consensos. O tempo pode ser físico ou social. O tempo físico é medido por aparelhos externos como relógios ou cronômetros enquanto tempo social é definido como "expressão da mudança ou do movimento dos fenômenos sociais em termo de outros fenômenos sociais" (RAMOS, I983, p. I8). O fenômeno consumo de um produto em um hospital, por exemplo, deve estar sincronizado ao fenômeno solicitação de compra.

A eficácia é influenciada ainda por elementos estruturais, os contextos mundiais, nacionais, e a sociedade interna de uma organização. Uma decisão pode ser concebida pelos atores das ações ou os indivíduos podem ter suas racionalidades influenciadas pela racionalidade do ambiente em que trabalham.

Ramos (1983) determina ainda o nível mais elementar do fato administrativo como "aestrutural" pelo fato dele ser amorfo. Cada instituição delimita as atitudes dos indivíduos. Um hospital tem uma missão diferente a uma fábrica de reciclagem, bem como uma estrutura logística quanto a instalações, prédios e utensílios. O autor exemplifica: "o compasso serve para uma coisa numa fábrica de tintas e para outra numa fábrica têxtil” (RAMOS, I983, p. Io). Objetos, instalações e sistemas são moldados por decisões. Um hospital também necessita de profissionais com perfis diferentes. Atitudes, estruturas e pessoas são únicas a cada organização.

\section{METODOLOGIA}

Após esclarecer o objeto e os conceitos, é fundamental descrever os métodos. Este estudo é qualitativo, procura "uma compreensão detalhada dos significados e características situacionais apresentadas" (RICHARDSON, I999, p. 90).

Neste trabalho, as relações entre conceitos e dados são fornecidas pelas categorias da Sociologia da Administração e a análise dos dados coletados no Hospital @ foi desenvolvida através de análise de conteúdo.

O corpus deste trabalho são os memorandos enviados e recebidos pelo setor de 2010 a 20I7. Weber e Durkheim, as inspirações de Ramos, também utilizaram documentos em suas pesquisas. Weber percebeu, através de registros cadastrais, que os indivíduos mais prósperos da sociedade americana eram adeptos da religião protestante. Durkheim (I983) utilizou dados públicos para identificar perfis de suicidas. 
Este trabalho também aprecia documentos e a percepção é consolidada seguindo as fases da análise de conteúdo indicadas por Bardin (20I0): pré-análise; codificação; categorização; tratamento dos resultados com a identificação de Unidades de Contexto (UCs), inferências e interpretação dos resultados.

$\mathrm{Na}$ fase de pré-análise, foram separados 249 documentos recebidos e enviados pelo almoxarifado em foco. Este artigo aprofunda um contexto detectado: a imprecisão do sistema operacional evidenciada em I6 documentos. A percepção do contexto é assegurada pela detecção de palavras-chave, a unidade de registro (UR) que: "capta os sentidos das comunicações em uma tarefa para codificar segmentos de conteúdo que se mostrem como unidade base" (DE ALBUQUERQUE, MARQUES, 20I6, p. II9). As palavras-chave compõem um processo de codificação e expõem que não há certeza do quanto se utiliza de insumos no local.

QUADRO I - Necessidade em precisar consumos

\begin{tabular}{|c|c|}
\hline Documentos & Conteúdo dos memorandos \\
\hline $\begin{array}{l}\text { 42/2015 - Enviado pela Unidade de } \\
\text { Nefrologia ao Almoxarifado }\end{array}$ & $\begin{array}{l}\text { Solicita esclarecimento. Em um mês, o consumo é de } 32 \\
\text { unidades e em outro mês é de } 5004 \text { unidades. }\end{array}$ \\
\hline $\begin{array}{l}\text { 21/2015 - Enviado pelo Almoxarifado } \\
\text { à Nefrologia }\end{array}$ & "O consumo do sistema não condiz com o real mensal". \\
\hline $\begin{array}{l}50,222 \text { e } 308 / 2015 \text { - Enviado pela } \\
\text { Nefrologia ao Almoxarifado }\end{array}$ & Informam consumos \\
\hline $\begin{array}{l}\text { 53/2016 - Enviado pelo Almoxarifado } \\
\text { à Nefrologia }\end{array}$ & $\begin{array}{l}\text { "Solicitamos atesto de que o material será consumido no prazo } \\
\text { de vencimento". }\end{array}$ \\
\hline $\begin{array}{l}\text { 72/2017 - Enviado pelo Almoxarifado } \\
\text { à Divisão de Logística }\end{array}$ & $\begin{array}{l}\text { Documento e sistema possuem informações conflitantes. A UR } \\
\text { "A última compra levou em consideração a média de consumo } \\
\text { mês do material indicada pelas saídas no sistema" (linhas } 2 \text { a } \\
\text { 4) está em conflito com a UR “o consumo atual do material, } \\
\text { conforme indicado pelo Setor de Nefrologia, é de } 10 \text { galões/ } \\
\text { mês" (linhas } 7 \text { e } 8 \text { ). }\end{array}$ \\
\hline $\begin{array}{l}28,29 \text { e } 30 / 2017-\text { Enviado pelo } \\
\text { Almoxarifado a três setores }\end{array}$ & Solicita consumo de materiais \\
\hline $\begin{array}{l}\text { 48/2017 - Enviado pelo } \\
\text { Serviço de Esterilização ao } \\
\text { Almoxarifado }\end{array}$ & Responde ao consumo solicitado pelo almoxarifado \\
\hline $\begin{array}{l}24 / 2017-\text { Enviado pelo Bloco } \\
\text { Cirúrgico ao Almoxarifado }\end{array}$ & Responde ao consumo solicitado pelo almoxarifado \\
\hline $\begin{array}{l}26 \text { e } 27 / 2017 \text { - enviado pelo Unidade } \\
\text { de Nefrologia }\end{array}$ & Informa consumo de materiais \\
\hline $\begin{array}{l}48 / 2017 \text { - Enviado pela Unidade de } \\
\text { Diagnóstico de Imagens }\end{array}$ & Informa consumo de materiais \\
\hline $\begin{array}{l}\text { Enviado pelo setor de oftalmologia ao } \\
\text { almoxarifado }\end{array}$ & Informa consumo de material \\
\hline
\end{tabular}

Fonte: arquivos do almoxarifado central do Hospital @, (20I7).

O objeto específico da pesquisa são estes documentos. A análise consiste da representação dos registros em figuras e na descrição dos elementos. Um retângulo preto é utilizado para cobrir a identidade dos atores em uma nova imagem que é detalhada. 
FIGURA I - Exemplo de documento anexado à análise

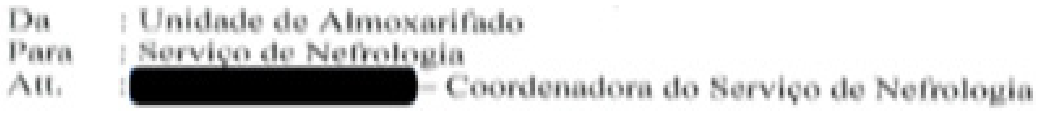

Assumto: Resposta nobre media de consumo de noluçoes àeidas e básieas.

Im resposta ao Memo 042/2015/Unidade de Nefrolosia eselareeomos que as diferencas de consumos mensais de soluços acidas omsicas no periodo de fevereiro de 2014 a janeiro de 2015 sâo decorrentes de lanģamentos de Requisiçoes de Materiais - RM's de um més para o outro subsequente - haja vista que findo o més da data da RM o nistema mpede' lançamentos retroativos, acarretando em somatório de produtos

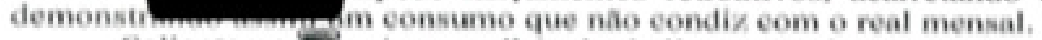

SalientamonThe of aconselhavel o balizamento do consumo pela media absoluta - total do consumo anual dividido por dore meses.

\section{Atenciosamente,}

Fonte: arquivos do almoxarifado central do Hospital @, 2017.

As palavras-chave detectadas nos documentos remetem a conceitos que são categorizados. Este trabalho utiliza o método weberiano dos tipos ideais, um método que "refere-se à construção de certos elementos da realidade numa concepção logicamente precisa" (WEBER, GERTH, MILLS, 1982, p. 78). Estes elementos variam em amplitude e no nível de abstração. O nível de amplitude e abstração das categorias é analisado dentro do seguinte esquema teórico:

QUADRO 2 - Categorização científica desenvolvida

\section{Tábua das categorias - sociologia das organizações}

Tipos Ideais da ação administrativa

\begin{tabular}{|c|c|}
\hline $\begin{array}{c}\text { Racionalidade Instrumental - os atores estão } \\
\text { focados no fim da ação }\end{array}$ & $\begin{array}{c}\text { Racionalidade Substantiva - os agentes alcançam } \\
\text { objetivos desenvolvendo valores pessoais }\end{array}$ \\
Tipos Ideais do Fato Administrativo \\
\hline $\begin{array}{c}\text { Nível Estruturante - Eficácia, tempo e } \\
\text { comunicação }\end{array}$ & $\begin{array}{c}\text { O conteúdo é classificado neste nível quando trata de } \\
\text { comunicação e tempo para gerar eficácia }\end{array}$ \\
\hline $\begin{array}{c}\text { Nível Estrutural - contexto mundial, global e e } \\
\text { interno da organização }\end{array}$ & $\begin{array}{c}\text { Este nível mensura o quanto os contextos externos } \\
\text { influenciam a decisão }\end{array}$ \\
\hline $\begin{array}{c}\text { Nível Aestrutural - Atitudes, Estrutura e } \\
\text { Pessoas }\end{array}$ & $\begin{array}{c}\text { Este nível avalia o quanto a morfologia da organização é } \\
\text { determinante à ação }\end{array}$ \\
\hline
\end{tabular}

Fonte: Ramos, 1983.

A abstração dos elementos determina se uma ação parte do indivíduo ou se é o ambiente organizacional que determina a ação que deve adotar. A amplitude avalia o grau em que esta ação é intrínseca ou extrínseca à pessoa. 
Ramos (I983) tem uma teoria que preconiza o ser humano à frente dos fatos administrativos. O teórico os representa na equação $n+$ I em que o $n$ são os elementos estruturais e aestruturais e o I são as ações das pessoas.

Quadro 3 - Equação n + I como forma de precisar a ação administrativa

\begin{tabular}{|l|}
\hline \multicolumn{1}{|c|}{ Equação } \\
\hline $\mathrm{n}+1=$ \\
$\begin{array}{l}\text { Substitui-se o n por um valor. Se ficar evidenciada uma ação baseada em um elemento estrutural (sociedade } \\
\text { mundial, global ou interna) ou em um elemento aestrutural (atitudes, estrutura ou pessoas), percebe-se } \\
\text { que a ação é fundamentada em um fator externo ao indivíduo e a equação adquire um valor de, pelo menos }\end{array}$ \\
$-1,1$, pois: $-1,1+1=-0,1$ \\
A equação tem um resultado negativo e demonstra um sistema desestruturado.
\end{tabular}

Fonte: Adaptado de Ramos, 1983

A análise determina a predominância dos níveis de decisão dos fatos e a racionalidade vigente. Se o domínio for de elementos externos, a racionalidade é instrumental e se for de elementos internos (comunicação e tempo), constata-se uma racionalidade substantiva. Uma ação determinada por normas internas ou uma cultura organizacional demonstra pouca participação do indivíduo. A decisão é condicionada. Abstração é um elemento interno extraído do ator em uma organização que não estimula valores individuais.

A detecção da Unidade de Contexto (UC) é evidenciada na descrição de ações e fatos. Após este processo, o trabalho apresenta um conceito de melhoras ao setor analisado. Há um registro que revela um método de gestão eficaz que pode ser replicado.

Este trabalho apresenta uma teoria positiva como a de Ramos (1983 e 1989) e o processo de inferência, etapa metodológica em que "o pesquisador analisa os dados baseado em um método científico, infere e projeta a realidade" (RODRIGUES, 2007), consiste no teste de um sistema administrativo focado na valorização de abstrações individuais para alcançar eficácia.

As bases da ação administrativa eficaz são identificadas e confrontadas com os elementos evidenciados como problemáticos. A inferência principal da análise consiste em detectar se um sistema evidenciado como eficaz pode beneficiar o setor de forma ampla.

A interpretação é composta por conclusões e recomendações para uma forma de gestão que apresenta possibilidades de estruturação do setor, libertação de fatores puramente técnicos e não-humanos e a construção de uma racionalidade substantiva.

\section{RESULTADOS}

O corpus desta análise são as ações e fatos registrados nos documentos enviados e recebidos pelo setor. O primeiro registro é o memorando $42 / 2015$, enviado pela Unidade de Nefrologia ao almoxarifado. Nesta comunicação, o chefe da nefrologia solicita um esclarecimento. De acordo com o sistema computacional, o consumo de um produto foi de 32 unidades em um mês e no mês seguinte, o consumo foi de 5.004 unidades. Este aumento de consumo em quase cinco mil unidades não faz sentido para o chefe da nefrologia. 
Figura 2 - Evidência da imprecisão do consumo

\title{
Assunto: Esclarecimentos sobre quantitativo mensal das soluç̋̄es dicida e bd́sica
}

Prezado, venho através deste solicitar esclarecimentos, conforme contato telefônico com o Sr. sobre o quantitativo mensal de soluç̋̃es ácida e básica liberadas para o serviço de nefrologia do periodo de fevereiro/ 2014 a janeiro/ 2015 .

De acordo com planilha apresentada pelo almoxarifado, percebemos desproporçőes em alguns meses, como por exemplo em novembro foram liberadas apenas 32 soluçð̃es básicas e em dezembro 5004. 32 soluçð̃es seriam insuficientes para um mès, já 5004 soluçđes seriam suficientes para abastecer aproximadamente 5 meses. quantitativos.

Os dados serão avaliados em reuniåo com a Diretoria e precisamos justificar os

Fonte: arquivos de um almoxarifado do Hospital @, 20I7

O gestor do almoxarifado responde ao chefe da nefrologia no memorando $2 \mathrm{I} / 2 \mathrm{I} 5 \mathrm{e}$ informa que "o consumo do sistema não condiz com o real mensal" e indica uma média ponderada para determinar o consumo.

FIGURA 3 - A necessidade de interpretar a informação do sistema

\author{
Da Unidade de Almoxarifado \\ Para Servigo de Nefrologia \\ Ail. Coordenadora do Serviço de Nefrologia
}

Assumto: Resposta nobre media de consumo de noluçoes áeidas e básieas.

Im resposta ao Memo 042/2015/Unidade de Nefrolosia esclarecemos que as diferencas de consumos mensais de solucoes aeid de 11/02/2015. Domicas no periodo de rem de decorrentes de lamentos de Requisiçoes de Materiais - RM's de um més para o outro subsequente - haja vista que findo o més da data da RM o nistema mpede'lançamentos retroativos, acarretando em somatório de produtos demonstinnmunmy-

Salientamos Tive of aconselhavel o balizamento do eonsumo pela media absoluta - total do consumo anual dividido por dore meses.

\section{Ateneiosamente,}

Fonte: almoxarifado central do Hospital @, 20I7.

Por estes registros, entende-se que o órgão utiliza um sistema computacional para determinar o consumo de materiais. Este sistema, no entanto, "não condiz com o real". No período analisado, a nefrologia emite ainda mais quatro documentos informando consumo de materiais, evidenciando uma necessidade de complementação aos dados do sistema.

Há indícios de um problema aestrutural. As pessoas produzem dados a partir da lógica de configuração organizacional que o sistema computacional pressupõe. O sistema fornece as informações sobre estoque e compra do material. Percebe-se, no entanto, um protagonismo do sistema na gestão de insumos do local. O sistema se torna estruturante. Dele decorre uma comunicação específica que surge entre as pessoas, estabelecendo uma práxis que orienta as bases racionais de suas relações funcionais. Muito embora se perceba, por parte de cada gestor, demonstrações de confiança na informação do sistema, estes recorrem a uma lógica organi- 
zacional que não é plenamente captada pelos memorandos, o que se supõe haver uma práxis racional distinta da comunicação institucional registrada nestes memorandos.

A partir da comunicação registrada, percebe-se uma verticalização, com o sistema fornecendo uma informação absoluta para o evento gerencial que representa. Esta informação, entretanto, precisa ser interpretada por cada gestor. O não entendimento pelo gestor da nefrologia passa a ser o novo registro que assume uma dimensão de questionamento ao almoxarifado. A nova informação é registrada e complementada por memorando.

As próximas evidências da falta de qualidade de informação são os memorandos 28, 29 e 30/20I7, confeccionados por um gestor do almoxarifado. Neles, o gestor solicita o consumo de materiais a diversos setores. Dois gestores respondem e fornecem a informação.

QUADRO 4 - Conteúdos de gestores informando consumos

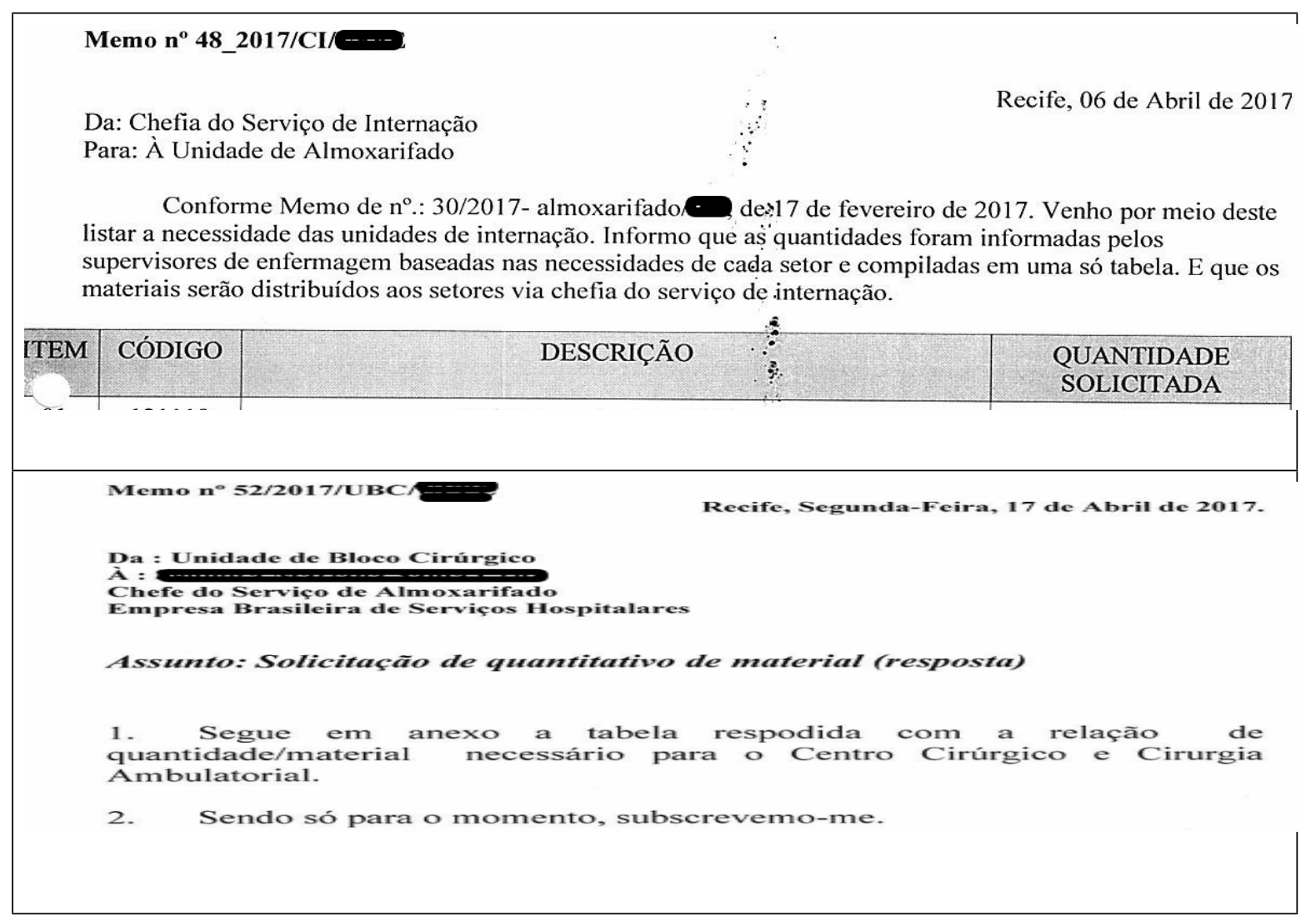

Fonte: almoxarifado central do Hospital @, 2017

No memorando 48/20I7 (primeira linha do Quadro 4), o gestor do serviço de esterilização detalha: "informo que as quantidades foram informadas pelos supervisores de enfermagem". Ao inserir este conteúdo no documento, o gestor do serviço de esterilização evidencia uma informação aproximada.

E novos indícios da imprecisão do sistema surgem no memorando 72/2017, enviado pelo chefe do almoxarifado ao gestor da Divisão Logística. Neste memorando, o gestor do almoxarifado informa a doação de um material. Há uma diminuição na demanda do insumo e o setor tem de doar o excedente. 
FIGURA 4 - Doação de material por causa da imprecisão do sistema

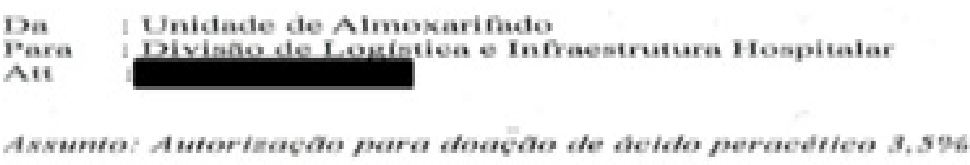

Nolieitamon autorivagho para doagho de 93 saloen de heido peraedieo 296 para

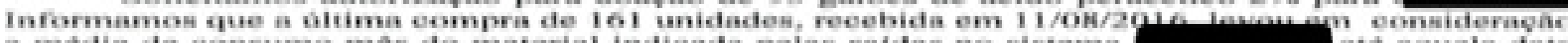
a media de consumo mes do material indieada pelas naidas no nistema $C$ (medis mensal - ontre jan e jul de 2016 - 6 i unidades), eontudo, eomo proxento observar pele

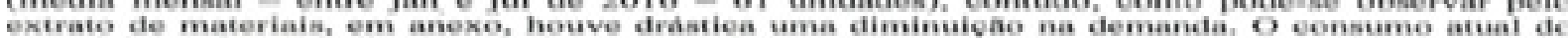

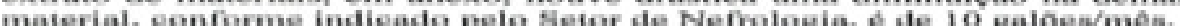

Diante do exposte, i $\mathrm{hm}$ de evitarmos perdas por veneimento, nolieite autorivagas para doa 70 saloes de deido peraedieg eonforme dados abaine

\begin{tabular}{|c|c|c|c|c|}
\hline Cot $1 \mathrm{AC}$ & Material & Beste & Valieteate & 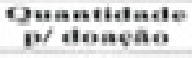 \\
\hline ดแ270 & 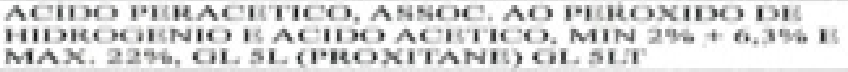 & 1306161 & $30 / 06 / 2017$ & 93 \\
\hline
\end{tabular}

I $\mathrm{m}$ tempo, informamos que o material foi ofereoido a rede pobliea. Rniretanto, naso houve interesse por parte dos hospitais que eontatamos. Informo que as novas aquisivoes noto realizadas om

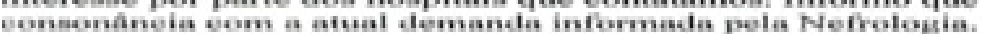

Fonte: Almoxarifado do Hospital @, 2017

As URs das linhas 2 e 3 "informamos que a última compra levou em consideração a média de consumo indicada pelo sistema" estão em conflito com as URs "o consumo atual do material, conforme indicado pelo Setor de Nefrologia, é de Io galões/mês", presentes nas linhas 7 e 8 do documento. De acordo com o método de Bardin (20I0), depreende-se destas URs um cenário em que a informação do setor é mais real à do sistema e que houve um problema na última compra por se levar em consideração apenas o sistema.

Há ainda mais quatro memorandos enviados por três setores diferentes - Nefrologia, Diagnóstico de Imagens e Oftalmologia, informando consumos de materiais. O sistema é aestrutural, mas se torna estrutural pelo fato de ser utilizado pela sociedade interna como um fator de distanciamento aos gestores. Os gestores racionalizam que é desnecessário se comunicar diretamente por haver um sistema que informa os dados do consumo, o que faz com que o sistema chegue ao nível estruturante, pois apenas ele é levado em consideração nas decisões. Estas evidências confirmam uma racionalidade:

QUADRO 5 - A falta de interpretação dos dados como um problema desestruturante

\begin{tabular}{|l|l|}
\hline \multicolumn{1}{|c|}{$\begin{array}{c}\text { Nível do fato } \\
\text { administrativo }\end{array}$} & \multicolumn{1}{c|}{ Característica } \\
\hline Aestrutural & O sistema reflete um consumo \\
\hline Estrutural & E se torna um intermediador da sociedade interna \\
\hline Estruturante & Com uma informação absoluta que determina as ações \\
\hline
\end{tabular}

Fonte: Elaborado pelos os autores, (2019)

Há uma inversão de valores: o sistema computacional é estruturante e as pessoas são aestruturais. Ramos (1983) teoriza que elementos aestruturais são "anárquicos se deixados à própria sorte”, mas no Hospital @ fica evidente que o sistema estrutura as decisões das pessoas e as pessoas estão à própria sorte sem ele. Gerencialmente, entretanto, evidencia-se que a informação do sistema necessita ser precisa.

No ano de 20I3, o gestor da Unidade de Esterilização produz memorandos com o con- 
teúdo-chave: "a falta do insumo acarretará a suspensão dos serviços", conteúdo idêntico ao presente no memorando 302/2015, da Unidade de Nefrologia: "caso o material não chegue, haverá interrupção nos procedimentos de hemodiálise no hospital" e a Unidade de Clínica Médica corrobora esta impressão quando também relata a necessidade urgente de aquisição de um material: "os atendimentos estão comprometidos", relata o gestor. Em 20I7, a Unidade de Transfusão realiza extensa explicação sobre a necessidade de aquisição de detergente alcalino. Estes conteúdos revelam uma relação insumo/atendimento.

QUADRO 6 - Evidências da relação insumo/atendimento

\begin{tabular}{|l|l|}
\hline \multicolumn{1}{|c|}{ Documentos } & \multicolumn{1}{|c|}{ Conteúdos } \\
\hline $\begin{array}{l}\text { 73, 74, 94, 120,148,193/2013 - Unidade de } \\
\text { Esterilização }\end{array}$ & "A falta do insumo acarretará a suspensão dos serviços" \\
\hline Memorando 302/2015- Nefrologia & $\begin{array}{l}\text { "Caso as soluções não cheguem, haverá interrupção nos } \\
\text { procedimentos" }\end{array}$ \\
\hline Memorando 17/2015 - Clínica Médica & "Os atendimentos estão comprometidos" \\
\hline Memorando 60/2017 - Unidade de Transfusão & $\begin{array}{l}\text { "Utilizamos esse detergente na limpeza e quando } \\
\text { ocorrem derramamentos. Logo, seu uso é fundamental..." }\end{array}$ \\
\hline
\end{tabular}

Fonte: almoxarifado central do Hospital @, 2017

Os documentos revelam que gestores ambulatoriais estão conscientes que não há atendimento sem material. Entretanto, percebe-se também uma inconsciência: não há registros de acompanhamento do estoque, apenas da falta do insumo, como pode ser observado com os memorandos apresentados no Quadro 7.

QUADRO 7 - Memorandos urgentes recebidos pelo almoxarifado

\begin{tabular}{|c|c|}
\hline Documentos & Conteúdos \\
\hline CI de 2010 - Pediatria & Solicita materiais pré-operatórios \\
\hline CI 176/2010 - Esterilização & Solicita material em caráter de urgência \\
\hline 74/2013 Esterilização & $\begin{array}{l}\text { "Solicitamos, em caráter de urgência, aquisição de insumo. A } \\
\text { falta impedirá a lavagem dos instrumentais nos procedimentos } \\
\text { cirúrgicos". }\end{array}$ \\
\hline 94/2013 Esterilização & $\begin{array}{l}\text { Seis dias após, a mesma situação, o gestor informa: "o estoque e que } \\
\text { só atenderá o dia de hoje. A falta do insumo acarretará a suspensão } \\
\text { dos serviços". }\end{array}$ \\
\hline 94/2013 Esterilização & $\begin{array}{l}\text { Utilizam a mesma numeração. Informa que estão sem detergente } \\
\text { Solicita a aquisição em caráter de urgência. }\end{array}$ \\
\hline 120/2013 Esterilização & $\begin{array}{l}\text { Novamente, a falta de detergente enzimático, utilizado para lavagem } \\
\text { de materiais cirúrgicos. }\end{array}$ \\
\hline 148/2013 Esterilização & Praticamente as mesmas sentenças informando pouco detergente. \\
\hline 193/2013 Esterilização & $\begin{array}{l}\text { CI para vários setores informando a necessidade de compra de } \\
\text { vários insumos em caráter de urgência. }\end{array}$ \\
\hline CI s/n 2013 - Endoscopia & Também relata a falta de detergente enzimático \\
\hline Memorando 17/2015 -Clínica Médica & $\begin{array}{l}\begin{array}{l}\text { Compra urgente de material -“Os atendimentos estão } \\
\text { comprometidos" }\end{array} \\
\end{array}$ \\
\hline Memorando 302/2015- Nefrologia & $\begin{array}{l}\text { "Se o insumo não for adquirido em dois dias, os atendimentos irão } \\
\text { paralisar" }\end{array}$ \\
\hline
\end{tabular}




\begin{tabular}{|l|l|}
\hline Memorando 08/2017 CCIH & $\begin{array}{l}\text { Informa inadequações. "Solicitamos recolhimento com compra } \\
\text { emergencial de substituto. Antes da compra, deverão ser enviadas } \\
\text { amostras para testagem para CCIH". }\end{array}$ \\
\hline 18/2017 - Unidade Transfusional & $\begin{array}{l}\text { Solicita Detergente Alcalino. URGENTE. } \\
\text { Explica a necessidade em negrito. Solicitamos aquisição o mais } \\
\text { breve possível. }\end{array}$ \\
\hline 22/2017 - Unidade Transfusional & Solicita insumos em caráter urgente \\
\hline $51 / 2017$ - Unidade Transfusional & Solicita insumos em caráter urgente \\
\hline $54 / 2017$ - Unidade Transfusional & Solicita um formulário urgentemente \\
\hline $60 / 2017$ - Unidade Transfusional & Solicita insumos em caráter urgente \\
\hline $51 / 2017$ - Esterilização & Solicita material urgente \\
\hline $52 / 2017$ - Esterilização & Solicita material urgente \\
\hline
\end{tabular}

Fonte: almoxarifado central do Hospital @, 2017

Uma das principais observações metodológicas de Bardin (2010) é observar o não-dito e não se percebe conteúdos que demonstrem o acompanhamento do estoque pelo almoxarifado e pelos setores que utilizam os insumos. Para Durkheim (1983): os fatos "possuem uma existência própria, independente das manifestações individuais" e é perceptível uma interpretação dos gestores de que o consumo de materiais é determinado por forças externas aos agentes sociais.

Trata-se de uma interpretação questionável. Médicos e enfermeiros desenvolvem uma ética de responsabilidade ao atendimento e não consideram que informar o estoque em tempo seja parte da ação. A informação de consumo adquire um contorno de existência própria em uma concepção semelhante à de Durkheim (1983). Não se percebe a relação estoque e atendimento e esta atitude gera um sério risco à gestão.

O maior exemplo de risco é uma urgência de insumo retratada em uma série de quatro memorandos. No primeiro, o 42/2015, o gestor da nefrologia solicita o consumo de um material. No segundo, o 2I/20I5, o gestor do almoxarifado explica que a informação do sistema não condiz com o "real mensal". No terceiro memorando, o 84/2015, evidencia-se que houve uma reunião para dirimir a dúvida do consumo, vide Figura 5.

FIGURA 5: Memorando que exemplifica a sociedade interna do hospital @

\section{Memo n" 0\$4/201s/Unidede de Nerrologit}

Recife, quaria-foira, 11 de marge de 2015.

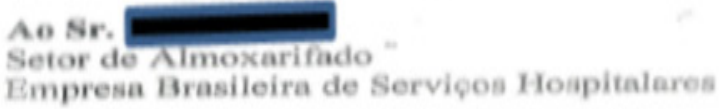

Assumioz Soluçes delda e bilsiod

Prezado, em virtude dos enoaminhamentos da reunilfo realizada no mess de fovereirc com a Diretoria, venho através deste solicitar que nos sejam fomedidos mensaimente, atravét do i-mail fó quantitativo de soluçeses ácidas e bésieas disponiveis em estoque

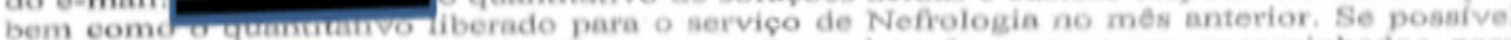
disponibilizar os dados as primeira semana de oada mes para serem encaminhados para Diretoria.

Fonte: almoxarifado central do Hospital @, 20I7. 
Uma reunião é um evento que procura um consenso, mas o documento revela que a reunião retratada no memorando 84/20I5 teve caráter instrumental. A repetição da UR "diretoria", bem como a presença da UR "encaminhamentos" assegura a inferência de que o gestor do almoxarifado é encaminhado à racionalidade do coordenador da nefrologia. Trata-se de uma característica autoritária da sociedade interna do Hospital@. A unidade ambulatorial encaminha a unidade gerencial à racionalidade do hospital. A abstração, os valores do gestor do almoxarifado são retirados e substituídos pelos da organização.

As evidências revelam um tipo de gestão fortemente hierárquico, mas não a eficácia desta atitude, ao contrário, o memorando 302/2015, confeccionado alguns meses após, relata que, apesar do encaminhamento racional, a gestão não se estruturou e há uma ameaça da falta do material retratado no memorando 84/20I5, vide Figura 6.

FIGURA 6 - Urgência causada pela falta de comunicação

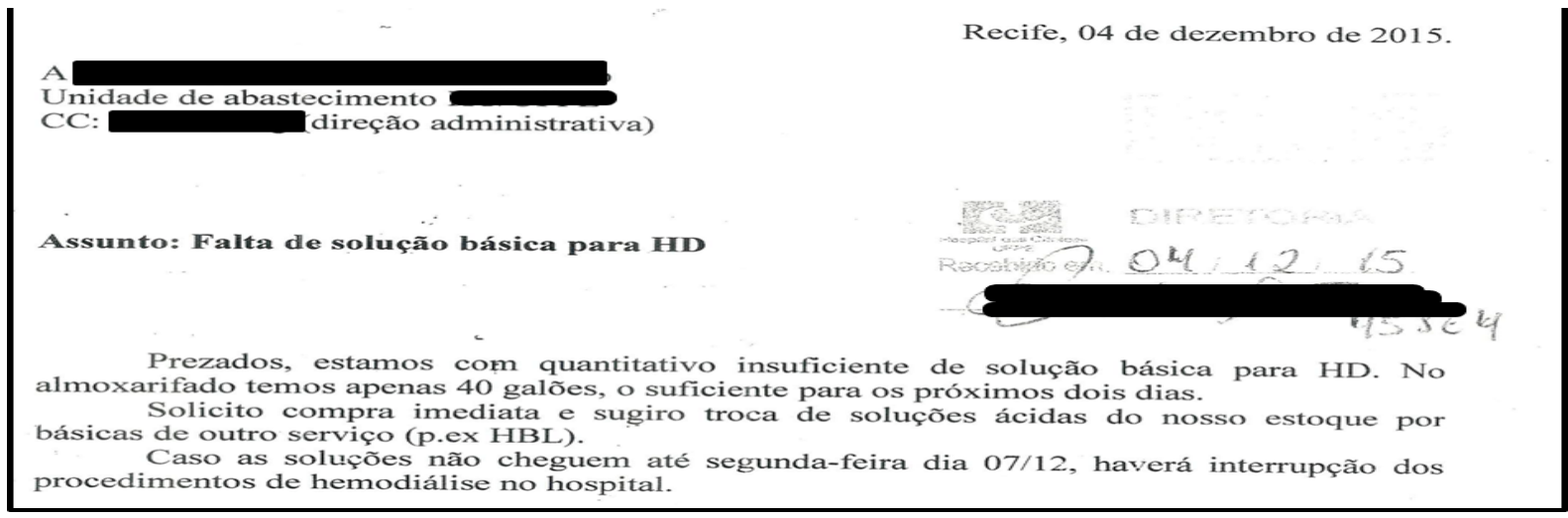

Fonte: almoxarifado do Hospital@, no ano de 2017

O encaminhamento à racionalidade dominante não é eficaz e há uma urgência com elementos descritos no Quadro 8.

QUADRO 8 - A Comunicação desestruturada causa urgência

\begin{tabular}{|c|c|}
\hline Documentos & Unidade de contexto - UC \\
\hline $\begin{array}{l}\text { 42/2015 - Enviados pela nefrologia ao } \\
\text { almoxarifado }\end{array}$ & $\begin{array}{l}\text { O gestor da nefrologia não entende o consumo de material } \\
\text { registrado no sistema }\end{array}$ \\
\hline $\begin{array}{l}\text { 21/2015 - Enviado pelo almoxarifado à } \\
\text { nefrologia }\end{array}$ & $\begin{array}{l}\text { O gestor do almoxarifado indica uma média ponderada do } \\
\text { consumo }\end{array}$ \\
\hline $\begin{array}{l}\text { 84/2015 - Enviado pela Unidade de } \\
\text { Nefrologia ao Almoxarifado }\end{array}$ & $\begin{array}{l}\text { O setor médico convoca uma reunião para definir um fluxo } \\
\text { indireto de comunicação, }\end{array}$ \\
\hline $\begin{array}{l}\text { 302/2015 - Enviado pela nefrologia ao } \\
\text { almoxarifado }\end{array}$ & $\begin{array}{c}\text { Ainda assim, a falta de comunicação entre os setores gera uma } \\
\text { situação em que só há material para dois dias }\end{array}$ \\
\hline
\end{tabular}

Fonte: Arquivos do almoxarifado central do Hospital @, 20I7

Esta é a situação mais tensa registrada no período analisado e exemplifica de forma qualitativa o problema da falta de comunicação em tempo em um centro de saúde.

Sobre comunicação em tempo, também é interessante ressaltar o envio de documentos do setor de esterilização para o almoxarifado no ano de 20I3. O setor trabalha com detergente 
enzimático para limpar materiais cirúrgicos e há uma escassez deste material no ano citado. $\mathrm{O}$ chefe da unidade envia cinco memorandos para o almoxarifado solicitando a compra do material. $\mathrm{O}$ interessante nos documentos é que o gestor aumenta o prazo da aquisição a cada memorando enviado, como pode ser observado no Quadro 9.

QUADRO 9 - A Procura por um tempo de referência

\begin{tabular}{|c|c|}
\hline $\begin{array}{l}\text { Tempo de } \\
\text { Referência }\end{array}$ & Documento \\
\hline $\begin{array}{l}\text { No primeiro } \\
\text { memorando, não } \\
\text { há um tempo de } \\
\text { referência. }\end{array}$ & 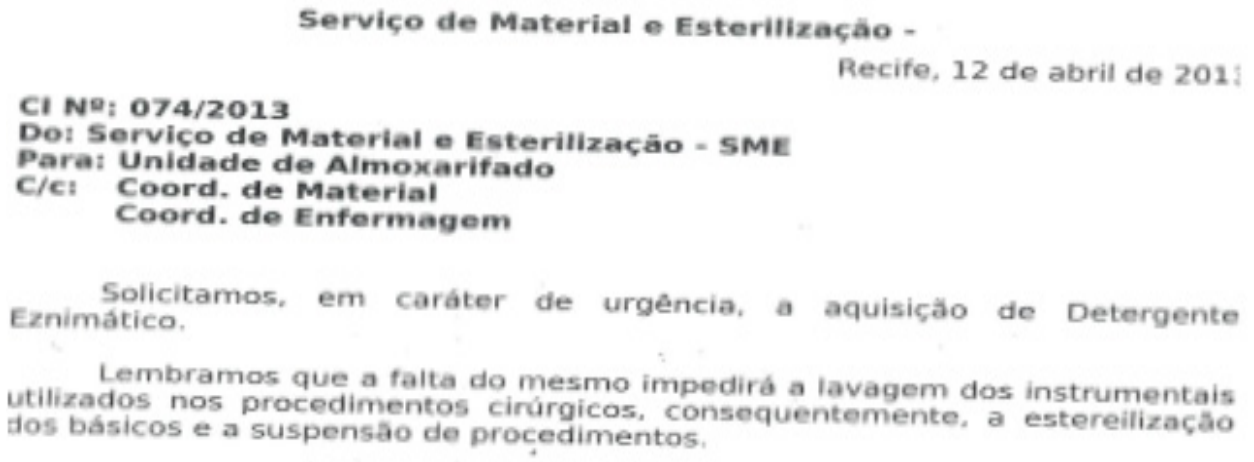 \\
\hline $\begin{array}{l}\text { Seis dias depois, } \\
\text { o memorando } \\
\text { (ao lado) possui } \\
\text { um tempo de } \\
\text { referência, mas } \\
\text { o material irá } \\
\text { acabar no mesmo } \\
\text { dia. } \\
\text { No mesmo dia 18, } \\
\text { novo memorando } \\
\text { é emitido } \\
\text { solicitando o } \\
\text { material. }\end{array}$ & $\begin{array}{l}\text { CI No: 094/2013 } \\
\text { Do: Serviço de Material e Esterilização - SME } \\
\text { Para: Unidade de-Almoxarifado } \\
\text { C/C: Diretoria Técnica } \\
\text { Coord. de Material } \\
\text { Coord. de Enfermagem } \\
\text { Reiterando a CI/SME no } 094 / 2013 \text {, do dia } 12 / 04 / 2013 \text {, informamos que } \\
\text { estamos com apenas } 2 \text { (dois) litros do detergente enzimático em uso, o que } \\
\text { atenderá apenas ao dia de hoje. Lembramos que a falta do referido detergente } \\
\text { impedirá a limpeza dos artigos, a esterilização e consequentemente a } \\
\text { suspensão dos procedimentos clínico e cirúrgicos. } \\
\text { Diante do exposto, sólicitamos a aquisição, em caráter de urgência, de } \\
\text { Detergente Eznimático. }\end{array}$ \\
\hline $\begin{array}{l}\text { No quarto } \\
\text { m e m o r a n d o, } \\
\text { se estabelece o } \\
\text { tempo de dois } \\
\text { dias. }\end{array}$ & 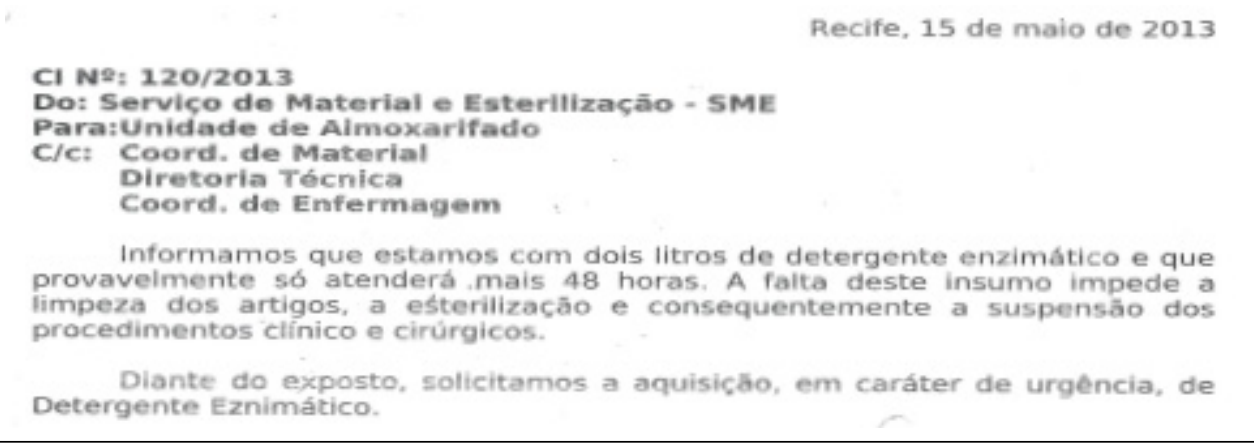 \\
\hline
\end{tabular}




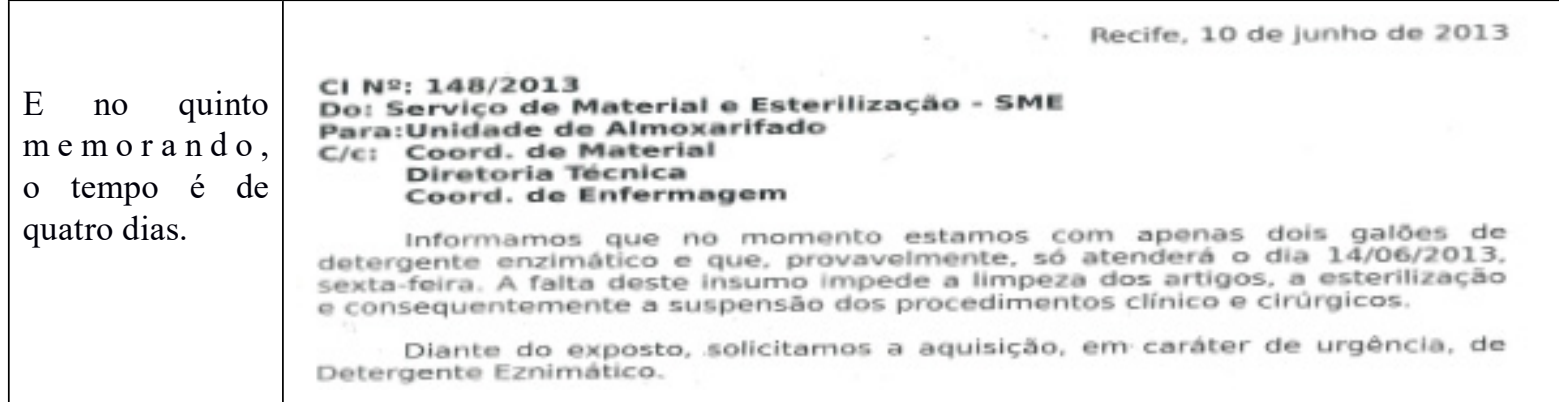

Fonte: Almoxarifado do Hospital @, 20I7.

É importante salientar a observação de Ramos de que "matemática é uma ciência da qual a decisão não toma parte" (RAMOS, I983, p. I5). Quem utiliza o insumo decide por quanto tempo 2 litros é suficiente. A falta de comunicação em tempo hábil torna o tempo emergencial. Percebe-se uma busca de gestores ambulatoriais e administrativos em determinar um tempo de referência tanto na ação do gestor da esterilização como na de um gestor do almoxarifado que solicita quantitativos a gestores ambulatoriais.

Há ainda outra questão temporal fundamental à compreensão da informação do consumo. Os setores solicitam o material através de formulários denominados Requisições de Material (RMs). Estas RMs são entregues no almoxarifado. Os servidores separam o material que é entregue aos setores. Os demandantes assinam o recebimento do material e as RMs são devolvidas aos servidores. É neste momento que os servidores preenchem os dados de consumo. No entanto, saídas de materiais não são o consumo e não representam a demanda.

Há carências de elementos aestruturais, pessoas (faltam servidores para registrar o consumo in loco) e condições/materiais de trabalho condizentes com o tipo de tarefa desenvolvida no setor. O sistema necessita de telas que reflitam o momento do consumo. A informação fornecida pelos servidores do almoxarifado no memorando 2I/20I5 reflete o momento da entrega do material. Há um atraso temporal na informação do consumo e este atraso explica o desencontro de informações entre os setores envolvidos, acarretando um tempo para a expedição de memorandos explicando e questionando a situação. Tempo este que poderia ser usado em outras frentes mais produtivas para a finalidade gerencial.

Neste ponto da análise, é importante utilizar a equação $n+$ I. Nela, a ação das pessoas é o I e os fatos administrativos são o n. O n deve ter um valor de, no máximo, - 0,9, pois, -0,9+ I=o,I. Evidencia-se que a informação do consumo no hospital @ apresenta um n + I negativo. Trata-se de uma reprodução de dados computacionais imprecisos que implicam, em algum momento, em retrabalho, logo em custos operacionais desnecessários.

QUADRO Io - A equação n + r no almoxarifado do hospital @

\begin{tabular}{|c|c|}
\hline Equação & Detalhamento \\
\hline $\begin{array}{l}\mathrm{n}+1=\text { O n é o sistema computacional (elemento } \\
\text { aestrutural) e não apresenta a informação do } \\
\text { consumo do produto. Trata-se, portanto, de um } \\
\text { valor de, pelo menos, }-1,1 \text { : } \\
-1,1+1=-0,1\end{array}$ & $\begin{array}{l}\text { O valor é negativo pelo fato de as pessoas (elementos } \\
\text { estruturantes) reagirem ao sistema (elemento } \\
\text { aestrutural) e não se comunicarem por causa } \\
\text { da sociedade interna fortemente hierarquizada } \\
\text { (elemento estrutural). }\end{array}$ \\
\hline
\end{tabular}

Fonte: Elaborado pelos autores, 20I9, à partir de Ramos (I983). 
A informação retratada não é o consumo. A interpretação errônea de que saída de material é consumo reflete uma instituição que estimula funcionários do tipo yesmen, aceitam ordens e atitudes sem critério crítico. O funcionário deste tipo toma por "janelas, o que são, na verdade, espelhos" (RAMOS, I983, p. 66). Um espelho não é uma janela e uma saída de material não é consumo. Fica evidente que a racionalidade que impera é instrumental pelo fato de os atores não desenvolverem uma relação pessoal, mediada por valores. Ao contrário, a relação institucional, por se operacionalizar via memorandos, torna-se impessoal e restrita ao registro da informação nestes memorandos. A postura dos servidores transforma a relação entre profissionais médicos e administrativos em uma relação entre profissionais e sistema computacional. Os servidores fornecem uma informação "técnica e não-humana" (MARQUES, 2007), tomam "relações entre homens como sendo, falsamente, relações entre coisas" (ALVES MOURÃO, 20I6, p. 70). A opção em se informar pelo sistema não desenvolve o poder de interpretação dos servidores e diminui as relações interpessoais. A abstração dos indivíduos é anulada em uma hierarquia elevada.

Metodologicamente, configura-se uma UC - Unidade de Contexto (BARDIN, 20Io). Há I6 documentos atestando imprecisão e a busca pela informação do consumo. Os registros descrevem um cenário de pouca qualidade na comunicação e no tempo do setor.

Percebe-se a necessidade de colocar os elementos nos locais corretos: o elemento aestrutural (sistema computacional) e estrutural (hierarquia organizacional) sendo moldados pelo elemento estruturante (pessoas se comunicando em tempo) para um fluxo gerencial positivo. Fortuitamente, há um exemplo com subsídios para a reversão conceitual necessária.

Ao ser questionado sobre materiais vencidos, o gestor do almoxarifado comunica no memorando 38/20I7 que "não há materiais vencidos na unidade" (grifo do gestor). O gestor relata que "o controle dos reagentes de laboratório é feito em parceria. Os pedidos de materiais químicos são realizados para um mês de consumo e o controle das validades é acompanhado de perto pelo chefe da Unidade de Laboratório".

FIGURA 7 - A eficácia em parceria

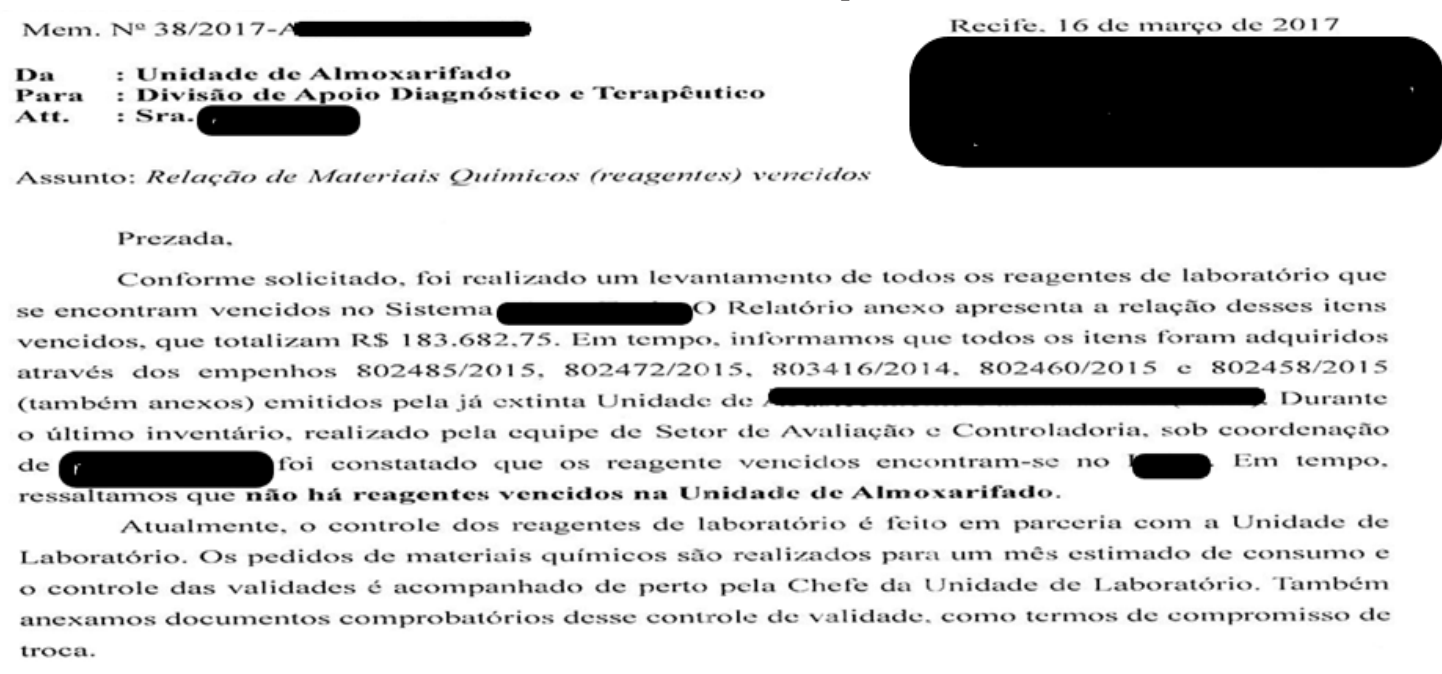

Atencjosamente,

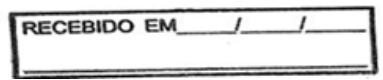

Fonte: almoxarifado central do Hospital @, 20I7 
O gestor do almoxarifado dá indícios de que há eficácia da gestão de materiais laboratoriais devido a uma "parceria com a Unidade de Laboratório". A gestão de insumos laboratoriais apresenta indícios de eficácia e serve para o desenvolvimento de uma categoria científica denominada nesta análise de Eficácia em Parceria.

A Eficácia em Parceria apresenta elementos como os descritos por Tenório (2006) em um modelo em que a aproximação das pessoas cria uma "gestão democrática". Dois gestores participam da ação e controlam consumos e validades. O documento é claro em apontar que a eficácia se deve a um "acompanhamento de perto", enquadrando-se na descrição da racionalidade substantiva.

Há também uma valorização da parceria. Termos positivos como os expressos no memorando 38/20I7 são únicos. O gestor do almoxarifado deseja demonstrar eficácia e Weber (20I2, p. 49-50) descreve um aspecto da racionalidade instrumental aplicável ao caso:

\begin{abstract}
A mais trivial das ações afeta o crédito de um homem. $\mathrm{O}$ som de seu martelo às cinco da manhã, ou às oito da noite, ouvido por um credor, o faz aguardar seis meses mais, mas se ele o vir numa mesa de bilhar, ou escuta sua voz numa taberna, quando você deveria estar trabalhando, ele solicita o pagamento no dia seguinte. Isto mostra, na verdade, que você se importa com o que deve, aparenta que você é cuidadoso bem como um homem honesto e isto aumenta seu crédito.
\end{abstract}

O crédito do gestor do almoxarifado ocorre, principalmente, quando os materiais não faltam. O gestor mostra aos superiores que "prega o martelo às cinco da manhã", e mais importante, que não está numa "mesa de bilhar", precisa demonstrar aos que o cobram que "se importa com o que deve". Neste memorando, o gestor do almoxarifado procura obter crédito por sua gestão plenamente consciente do cenário desfavorável no qual se encontra.

O almoxarifado registra 47 situações de escassez financeira, 35 atrasos nas entregas, 3I urgências de materiais (entre documentos recebidos e enviados) e 25 desabastecimentos de 2010 a 2017:

QUADRO II - Relação entre causas do desabastecimento e documentos

\begin{tabular}{|c|c|}
\hline Causas & Quantidade de documentos \\
\hline $\begin{array}{c}\text { Escassez de recursos } \\
\text { Financeiros }\end{array}$ & $\begin{array}{c}47 \text { documentos solicitando verbas ao Setor Financeiro } \\
\text { e de Suprimentos }\end{array}$ \\
\hline $\begin{array}{c}\text { Atraso na entrega de } \\
\text { produtos }\end{array}$ & $\begin{array}{c}35 \text { documentos solicitando a notificação de } \\
\text { fornecedores que atrasam nas entregas }\end{array}$ \\
\hline Urgências & 31 documentos -19 recebidos e 12 enviados \\
\hline
\end{tabular}

Fonte: Almoxarifado Central do Hospital @, 2017

A detecção destes documentos fornece dados para a percepção de um contexto problemático, uma UC - Unidade de Contexto - que evidencia o desafio de fornecer suprimentos à rede gratuita de saúde. O próximo passo da análise, de acordo com Bardin (20I0), é a construção de inferências. 


\section{DISCUSSÃO}

Inferências são pressupostos baseados em evidências, metodologia e teoria (BARDIN, 20I0). Os objetivos específicos desta análise são analisar os elementos que distanciam a gestão dos pontos ideais dos fatos e ações administrativas e uma forma de alcançá-los. Evidencia-se que os elementos negativos são a rígida cadeia hierárquica (elemento estrutural) e o sistema computacional (elemento aestrutural).

O ponto ideal detectado é um sistema de equação $n+$ I positivo em que a hierarquia seja mais consensual e as informações do sistema não sejam absolutas. Para alcançar o sistema administrativo positivo, é percebida uma Eficácia em Parceria com indícios de eficácia. Analisando a situação, chega-se às bases racionais da eficácia em parceria:

"Não há materiais vencidos na unidade. O controle é feito em parceria com a Unidade de Laboratório. Os pedidos de materiais químicos são realizados para um mês estimado de consumo e o controle das validades é acompanhado de perto pelo chefe da Unidade de Laboratório".

Unindo as URs com as categorias teóricas e aplicando estas bases a outros setores, tem-se que:

- O Problema Aestrutural do Sistema: Percebe-se que o sistema não é central na relação entre os gestores na eficácia em parceria. Ao checar o estoque de perto, os gestores não se valem de informações em telas de computador. Infere-se então que a parceria produz um acompanhamento in loco do gestor ambulatorial e que este possuirá informações realistas. Percebe-se que o problema da informação errônea de consumo seria solucionado.

- A informação do consumo não é independente da atuação dos gestores, consegue-se uma situação oposta à qual Durkheim (1983) preconiza para fatos sociais. Há um protagonismo dos atores.

- O Problema Estrutural da Configuração Interna Hierárquica: O maior exemplo de hierarquia das práxis médica e administrativa é o memorando $84 / 2015$, no qual o gestor da Unidade de Nefrologia encaminha ao gestor do almoxarifado a sua racionalidade, extraindo todo valor abstrato que o gestor do almoxarifado possa ter. Esta hierarquia cria uma racionalidade que enfraquece o critério crítico. Senso crítico, entretanto, é fundamental na gestão da informação do consumo dos materiais.

- A eficácia em parceria consegue diminuir a distância hierárquica. A situação de parceria apontada pelo gestor do almoxarifado expõe que os dois gestores controlam consumos e validades de forma igualitária. Evidencia-se que a racionalidade em parceria pode diminuir a rigidez na estrutura hierárquica entre os envolvidos, sem, contudo, perder eficácia, pelo contrário, as evidências apontam para seu aumento.

- O Problema Estruturante da Falta de Comunicação: Percebe-se ainda que a eficácia em parceria produz uma comunicação mais pessoal e otimizadora da eficácia organizacional no hospital. Há conteúdos que registram a articulação da comunicação e do tempo próximos ao problematizado por Ramos (I983). Como consequência desta aproximação, temos: "os pedidos de materiais químicos são realizados para um mês estimado de consumo e o controle das validades é acompanhado de perto pelo chefe da Unidade de 
Laboratório" (memorando 38/20I7, almoxarifado, linhas II a I3).

Os gestores determinaram um mês como prazo ideal para aquisições de materiais em uma combinação entre comunicação e tempo para gerar eficácia. Há ganhos qualitativos se a eficácia em parceria for replicada para a relação com outros setores.

\section{CONSIDERAÇÕES FINAIS}

Desta forma, a Eficácia em Parceria é uma resposta gerencial a todos os níveis da organização. A tríade evidências, teoria e metodologia contribuem à eficácia a partir da adoção de uma práxis racional mediada por valores, ou simplesmente, pela racionalidade substantiva.

A pesquisa alcança os dois objetivos específicos. A análise percebe que os elementos que distanciam a gestão de um sistema administrativo positivo são a estrutura hierárquica e o sistema computacional e a que a forma de aprimorar a gestão é através da eficácia da parceria anotada pelos gestores do laboratório e do almoxarifado.

As evidências revelam ainda o segundo setor com quem buscar uma parceria: a Unidade de Nefrologia. Das I6 demandas sobre consumos no período analisado, oito dizem respeito ao setor nefrológico. Uma sugestão prática são encontros mensais. De acordo com os relatos documentados, este período seria suficiente para garantir o acompanhamento do consumo e dos prazos de validade.

O tempo da ação deve se basear em uma equação $n+$ I em que o $n$ são fatos e o I é a ação gerencial. Há dois fatores n para a compra do material. O gestor deve estruturar sua decisão na informação quantitativa dos dados do sistema e deve qualificá-la com as informações dos gestores ambulatoriais. Desta forma, as bases racionais para uma eficácia em parceria são, conforme nível gerencial:

- Aestrutural/ Estrutura/ Pessoas: O sistema deve possuir telas de consumo;

- Para isto, são necessários funcionários operando o sistema nos setores ambulatoriais para que o consumo seja retratado in loco;

- Estrutural/Sociedade Interna: Dividir responsabilidades e o bônus das ações para diminuir a rígida hierarquia;

- Estruturante/Comunicação/Tempo: Realizar encontros com os gestores dos ambulatórios, no prazo máximo de um mês.

A contribuição deste artigo é a introdução do conceito da Eficácia em Parceria. De acordo com Ramos (1983), eficácia é a combinação de meios e recursos para atingir objetivos pré-determinados. Este trabalho demonstrou que eficácia no almoxarifado do Hospital @ é a combinação de meios e recursos através de parcerias. 


\section{REFERÊNCIAS}

ALVES MOURÃO, Victor Luiz. Temporalização do espaço social: apontamentos para uma sociologia do tempo. Ciências Sociais Unisinos, v. 52, n. I, 2016.

BARDIN, Laurence. Análise de conteúdo. São Paulo: Edições 70, 2010.

DE ALBUQUERQUE, URQUIZA, Marconi; MARQUES, Denilson Bezerra. Análise de conteúdo em termos de Bardin aplicada à comunicação corporativa sob o signo de uma abordagem teórico-empírica. Entretextos, v. I6, n. I, p. II5-I44, 2016.

DURKHEIM, Emile. O que é fato social. As regras do método sociológico, São Paulo, editora Ática, I983. v. 6.

MARQUES, Denílson Bezerra. Posicionamento Teórico sobre a noção de rede sociotécnica e de ator-rede. In: CONGRESSO BRASILEIRO DE SOCIOLOGIA, I3., 2007, Recife. Anais [...]. Recife: editora UFPE, 2007.

MOTTA, Paulo Cesar Delayfi. Ambiguidades metodológicas do just-in-time. Organizações \& Sociedade, v. 4, n. 7, p. II7-I3I, I996.

RAMOS, Alberto Guerreiro. A nova ciência das organizações: uma reconceituação da riqueza das nações. Rio de Janeiro: Fundação Getúlio Vargas, 1989.

RAMOS, Alberto Guerreiro. Administração e contexto brasileiro: esboço de uma teoria geral da administração. Rio de Janeiro: Fundação Getúlio Vargas, I983.

RICHARDSON, Roberto Jarry. Pesquisa social: métodos e técnicas. 3. ed. São Paulo: Atlas, 2009 .

RODRIGUES, William Costa et al. Metodologia científica. Paracambi: Faetec/IST, editora Phorte, p. 2-20, 2007.

TENÓRIO, Fernando G. A flexibilização organizacional: referencial técnico-organizacional. flexibilização organizacional: mito ou realidade. Rio de Janeiro: FGV, p. I29-24I, 2000.

TENÓRIO, Fernando G. A trajetória do Programa de Estudos em Gestão Social (PEGS). Revista de Administração Pública, Rio de Janeiro, editora FGV, v. 4O, n. 6, p. II45-II62, 2006.

WEBER, Max. Economia e sociedade: fundamentos da sociologia compreensiva. Brasília: UnB, p. 209-227, I999. v. I

WEBER, Max. Ciência e política: duas vocações. São Paulo: Editora Cultrix, 2004.

WEBER, Max; GERTH, Hans Heinrich; MILLS, Charles Wright. Ensaios de sociologia. Rio 
de Janeiro: editora LTC, 1982.

WEBER, Max. La ética Protestante y Elespíritudel Capitalismo. Fondo de cultura económica, $20 \mathrm{I} 2$. 